\title{
Visfatin: A potential biomarker for the early diagnosis and monitoring of acute coronary syndrome
}

\author{
Yesim Guvenc', Serap Cuhadar', Ozgur Bayturan33, Cevval Ulman', (i) Gonul Dinc Horasan ${ }^{4}$, \\ Ozan Utuk ${ }^{3}$, Mahmut Acar ${ }^{3}$
}

'Department of Medical Biochemistry, Manisa Celal Bayar University Faculty of Medicine, Manisa, Turkey

${ }^{2}$ Department of Clinical Biochemistry, Ataturk Training and Research Hospital, Izmir, Turkey

${ }^{3}$ Department of Cardiology, Manisa Celal Bayar University Faculty of Medicine, Manisa, Turkey

${ }^{4}$ Department of Public Health, Manisa Celal Bayar University Faculty of Medicine, Manisa, Turkey

\begin{abstract}
Objectives: Acute coronary syndrome (ACS) is a major cause of mortality and morbidity worldwide; thus, early diagnosis is very important. The most common cause of ACS is the rupture of a vulnerable atherosclerotic plaque in the coronary artery, an occurrence in which inflammation plays a key role. The aim of the present study was to investigate visfatin as a proinflammatory biomarker in the early diagnosis and monitoring of ACS and to compare visfatin's relationship with troponin T, tumor necrosis factor-alpha (TNF-a), and creatine kinase-MB (CK-MB).

Methods: Sixty ACS patients and 30 healthy control subjects were enrolled in this study. One blood sample was drawn from the control participants, and 3 were obtained from the ACS patients at intervals 0-6 hours (T0), 6-12 hours (T1), and 12-24 (T2) hours from the start of chest pain. Serum visfatin, TNF-a, troponin T, and CK-MB levels were assessed. Visfatin and TNF-a levels were assessed using enzyme-linked immunosorbent assay testing, troponin T was evaluated using chemiluminescence, and CK-MB by enzymatic methods.

Results: Serum TNF-a, troponin T, and CK-MB levels in the T0 blood samples were statistically significantly higher in the ACS patients compared with the controls $(p=0.004, p<0.001, p<0.001$, respectively). A significant positive correlation was observed between visfatin and troponin $\mathrm{T}(\mathrm{r}=0.290, \mathrm{p}=0.007)$ in the T0 samples. Visfatin concentrations were lower in the ACS group in the T0, T1 and T2 samples $[4.01 \pm 6.23 \mathrm{ng} / \mathrm{mL}, 1.80 \pm 3.47 \mathrm{ng} / \mathrm{mL}$, and $1.72 \pm 2.67 \mathrm{ng} / \mathrm{mL}$, respectively; $\mathrm{p}=0.005 ; \mathrm{T} 0>(\mathrm{T} 1=\mathrm{T} 2)]$.

Conclusion: Visfatin had a significant positive correlation with troponin T. Visfatin did not demonstrate a rise and fall pattern like the standard biomarkers in terms of monitoring the progress of ACS patients, as there was a significant decrease after the first 6 hours. Although visfatin did not demonstrate superiority to troponin, its efficiency in a multimarker panel merits further evaluation. The role of visfatin in the early phase of pathophysiological mechanisms requires additional investigation.
\end{abstract}

Keywords: Acute coronary syndrome, adipokines, troponin T, tumor necrosis factor-alpha, visfatin

C oronary artery disease, which is the most common type of heart disease, is the leading cause of death for both sexes. Therefore, early diagnosis is crucial [1]. According to the statistics, the annual direct and indirect costs in the USA were about $\$ 310$ billion in 2009 [2].
Acute coronary syndrome (ACS), defined as a group of symptoms originating from the occlusion of coronary arteries, ranges from ST-segment elevated myocardial infarction (STEMI) and non-ST-segment elevation (NSTEMI) to unstable angina pectoris (UAP) [3]. ACS occurs with atherosclerotic

Address for correspondence: Yesim Güvenc, MD. Department of Medical Biochemistry, Manisa Celal Bayar University Faculty of Medicine, Manisa, Turkey Phone: +90 2362331920 / 346 E-mail: yesim.guvenc@gmail.com ORCID: 0000-0001-5640-0079

Submitted Date: August 16, 2018 Accepted Date: September 28, 2018 Available Online Date: January 12,2019

${ }^{\circ}$ Copyright 2018 by International Journal of Medical Biochemistry - Available online at www.internationalbiochemistry.com OPEN ACCESS This work is licensed under a Creative Commons Attribution-NonCommercial 4.0 International License. 
plaque rupture or erosion, followed by thrombus formation and arterial occlusion. Inflammation is associated with all forms of atherosclerotic plaques [3, 4].

Adipose tissue secretes several adipocytokines, including visfatin, leptin, adiponectin, omentin-1, and tumor necrosis factoralpha (TNF-a). These adipokines play an important role in the pathogeneses of insulin resistance, diabetes mellitus, dyslipidemia, inflammation, and atherosclerosis [5, 6]. TNF-a, a proinflammatory cytokine and a main mediator of inflammation, is predominately expressed in atherosclerotic lesions $[7,8]$.

Visfatin, a $52 \mathrm{kDa}$ protein, is an adipokine originally discovered in the liver, skeletal muscle, and bone marrow as a growth factor for B lymphocyte precursors. It was first named pre-B-cell colony enhancing factor [9-11]. Visfatin, suggested to be an insulin-mimetic adipokine, is mainly produced in adipose tissue and macrophages. Visfatin displays a proinflammatory action and is localized in macrophage foam cells $[12,13]$. According to 1 study, visfatin and TNF-a levels demonstrated a positive correlation with a radiographic progression of atherosclerosis in patients with rheumatoid arthritis [14]; thus, they might be useful markers for disease progression in the early stages.

Biomarkers play important roles in the diagnosis, risk assessment, and monitoring of patients with ACS. Today, troponins, creatine kinase-MB (CK-MB), and myoglobin are popular markers used in the early diagnosis and monitoring of ACS. However, the previously advocated use of myoglobin as an early marker of ACS has recently been discouraged, mainly because of its poor performance compared with precise and sensitive troponin assays $[15,16]$. Investigations continue for the means to identify patients with ACS and make earlier coronary intervention possible.

There are some studies in the literature investigating the serum visfatin level in metabolic syndrome and myocardial infarction (MI). However, to the best of our knowledge, there are no studies examining visfatin as a proinflammatory biomarker for monitoring ACS. The aim of the present study was to investigate visfatin as a biomarker in the early diagnosis and monitoring of ACS and to evaluate its relationship with troponin T, TNF-a, and CK-MB.

\section{Materials and Methods}

\section{Study subjects}

Sixty ACS patients (Group 1) and 30 control subjects (Group 2) were recruited into this study. Thirty healthy participants were selected from among hospital staff volunteers as a control group who were matched for age, gender, and body mass index (BMI) with the patients. This study was conducted in accordance with the Declaration of Helsinki and was approved by the medical ethics committee of Manisa Celal Bayar University Faculty of Medicine (approval number: 20478486-0.50.04.04). All of the participants in the study supplied informed consent and answered a questionnaire prepared for their health records. The ACS patient group was selected from consecu- tive adults admitted to the emergency department with acute chest pain. The diagnosis was established as coronary heart disease according to clinical symptoms, electrocardiogram findings, and cardiac markers, and confirmed with coronary angiography performed using a femoral access in the cardiology department of Manisa Celal Bayar Hospital.

Patients presenting with dyspnea after a trauma or malignancy, and patients who declined to participate in the study were excluded. Other exclusion criteria were the presence of diabetes mellitus, chronic inflammatory disease, liver disease, muscle disease, chronic renal failure, or a previous coronary angiography.

\section{Sample collection}

Venous blood samples were collected 3 times from the patients at intervals of 0-6 hours (T0), 6-12 hours (T1), and 12-24 hours (T2) after the onset of the first symptoms. The controls provided a single venous sample. All of the blood samples were collected into serum separator tubes, centrifuged at $3000 \mathrm{~g}$ for 4 minutes at $4^{\circ} \mathrm{C}$, and the sera samples were stored at $-80^{\circ} \mathrm{C}$ until analysis.

\section{Assay methods}

The serum visfatin levels were assessed using the enzymelinked immunosorbent assay (ELISA) method and a Human Visfatin ELISA Kit (Alpco Diagnostics, Salem, NH, USA). The sensitivity was $30 \mathrm{pg} / \mathrm{mL}$, the intra-assay coefficient of variation (\%CV) was 4.31, and the inter-assay $\% \mathrm{CV}$ was 7.58 . The TNF-a levels were also assessed using the ELISA method with a commercial kit (Biosource, Europe S. A., Nivelles, Belgium). The sensitivity was $1.7 \mathrm{pg} / \mathrm{mL}$, the intra-assay $\% \mathrm{CV}$ was 4.4 , and the inter-assay \%CV was 7.5. The serum troponin T levels were determined using the chemiluminescence method (Elecsys 2010; Hitachi, Tokyo, Japan). Serum glucose, urea, creatinine, aspartate aminotransferase, alanine aminotransferase, lactate dehydrogenase, CK-MB, triglyceride, cholesterol, high-density lipoprotein cholesterol, and low-density lipoprotein cholesterol levels were assessed with an auto-analyzer (Synchron Unicel DXC 800; Beckman Coulter, Fullerton, CA, USA) and commercial kits (Beckman Coulter, Inc., Brea, CA, USA). BMI was calculated using the formula of weight $(\mathrm{kg}) /$ height $(\mathrm{m})^{2}$.

\section{Statistical analysis}

There were 60 members in the patient group and 30 control participants. The 30 controls were included in order to perform parametric distribution and parametric tests.

SPSS for Windows, Version 15.0 (SPSS Inc., Chicago, IL, USA) was used to conduct the statistical analysis. Normality assessments were conducted using the Shapiro-Wilk test. Student's t-test and the Mann-Whitney $U$ test were used for normal and non-normally distributed data, as appropriate. In repeated measurement analyses (dependent groups) the Friedman nonparametric test was used. Post hoc nonparametric com- 
parisons were also performed using the Wilcoxon test. Chisquare tests were used for the comparison of categorical variables. Continuous variables were compared using Pearson correlation analysis. A type I error of 0.05 was accepted for all of the comparisons.

\section{Results}

Sixty ACS patients matched for age, gender, and BMI with 30 thirty control subjects were included in the study. The demographic data and routine biochemical parameters of the study groups are shown in Table 1. The visfatin, TNF-a, troponin T, and CK-MB level results at T0 are displayed in Table 2. The visfatin levels were not statistically higher in ACS patients than in the controls at $\mathrm{TO}(4.01 \pm 6.23$ vs. $1.46 \pm 1.18 ; p=0.128)$. The changes in the level of visfatin, TNF-a, troponin T, and CK-MB at T0, T1, and $\mathrm{T} 2$ are presented in Table 3. The visfatin level was highest at T0; the T1 and T2 levels were statistically significantly lower than that of T0. There was no significant difference between $\mathrm{T} 1$ and $\mathrm{T} 2$ in the visfatin level. Correlations between visfatin and troponin T, TNF- $a$, and CK-MB at T0 are shown in Table 4. In

\begin{tabular}{|c|c|c|c|}
\hline & $\begin{array}{l}\text { ACS } \\
(n=60) \\
\text { mean } \pm S D\end{array}$ & $\begin{array}{l}\text { Control } \\
(n=30) \\
\text { mean } \pm S D\end{array}$ & P value \\
\hline Age (years) & $61.50 \pm 13.53$ & $60.40 \pm 5.03$ & $0.669^{*}$ \\
\hline \multicolumn{4}{|l|}{ Sex } \\
\hline Male (\%) & $46(76.7)$ & $22(73.3)$ & $0.729^{* *}$ \\
\hline Female (\%) & $14(23.3)$ & $8(26.7)$ & \\
\hline BMI $\left(\mathrm{kg} / \mathrm{m}^{2}\right)$ & $24.86 \pm 2.68$ & $25.02 \pm 3.05$ & $0.810^{*}$ \\
\hline Glucose (mg/dL) & $100.08 \pm 10.38$ & $96.13 \pm 12.41$ & $0.115^{*}$ \\
\hline AST (U/L) & $55.33 \pm 56.18$ & $23.13 \pm 4.11$ & $0.001^{* * *}$ \\
\hline $\mathrm{ALT}(\mathrm{U} / \mathrm{L})$ & $27.03 \pm 16.16$ & $21.47 \pm 7.71$ & $0.078^{*}$ \\
\hline LDH (U/L) & $179.12 \pm 45.44$ & $157.96 \pm 28.84$ & $0.032^{*}$ \\
\hline Cholesterol (mg/dL) & $178.00 \pm 50.29$ & $177.63 \pm 25.46$ & $0.970^{*}$ \\
\hline $\mathrm{HDL}-\mathrm{C}(\mathrm{mg} / \mathrm{dL})$ & $34.56 \pm 9.78$ & $35.66 \pm 10.10$ & $0.619^{*}$ \\
\hline LDL-C (mg/dL) & $118.73 \pm 34.92$ & $115.53 \pm 20.59$ & $0.646^{*}$ \\
\hline Triglyceride (mg/dL) & $132.10 \pm 149.12$ & $134.67 \pm 59.46$ & $0.141^{* * *}$ \\
\hline Urea $(\mathrm{mg} / \mathrm{dL})$ & $35.72 \pm 15.24$ & $32.37 \pm 9.23$ & $0.272^{*}$ \\
\hline Creatinine (mg/dL) & $0.99 \pm 0.27$ & $0.99 \pm 0.18$ & $0.976^{*}$ \\
\hline \multicolumn{4}{|l|}{ Hypertension } \\
\hline Yes (\%) & $32(53.3)$ & $17(56.7)$ & $0.765^{* *}$ \\
\hline No (\%) & $28(46.7)$ & $13(43.3)$ & \\
\hline \multicolumn{4}{|l|}{ Smoker } \\
\hline Yes (\%) & $33(55.0)$ & $16(53.3)$ & $0.881^{* *}$ \\
\hline No (\%) & $27(45.0)$ & $14(46.7)$ & \\
\hline
\end{tabular}

*Student's t test; ${ }^{* *}$ Chi-square test; ${ }^{* * *}$ Mann-Whitney U test.

Categorical variables are expressed as $n(\%)$

ACS: Acute coronary syndrome; ALT: alanine aminotransferase; AST: aspartate aminotransferase; BMI: body mass index; HDL-C: high-density lipoprotein cholesterol; LDH: lactate dehydrogenase; LDL-C: low-density lipoprotein cholesterol.
Table 2. Data on visfatin, TNF- $a$, troponin T, and CK-MB in the study groups during $\mathrm{TO}$ *

\begin{tabular}{llll}
\hline & $\begin{array}{l}\text { ACS } \\
(\mathbf{n}=60) \\
\text { mean } \pm \text { SD }\end{array}$ & $\begin{array}{l}\text { Control } \\
(\mathbf{n}=\mathbf{3 0}) \\
\text { mean } \pm \text { SD }\end{array}$ & P value \\
\hline Visfatin $(\mathrm{ng} / \mathrm{mL})$ & $4.01 \pm 6.23$ & $1.46 \pm 1.18$ & $0.128^{* *}$ \\
TNF-a $(\mathrm{pg} / \mathrm{mL})$ & $12.77 \pm 6.08$ & $9.22 \pm 2.02$ & $0.004^{*}$ \\
TroponinT $(\mathrm{ng} / \mathrm{mL})$ & $1.74 \pm 3.49$ & $0.02 \pm 0.03$ & $<0.001^{* *}$ \\
CK-MB $(\mathrm{U} / \mathrm{L})$ & $23.56 \pm 28.04$ & $2.83 \pm 1.71$ & $<0.001^{* *}$ \\
\hline
\end{tabular}

*Student's t-test; **Mann-Whitney U test.

T0: 0-6 hours from onset.

ACS: Acute coronary syndrome; CK-MB: creatine kinase-MB; TNF-a: tumor necrosis factor alpha.

the T0 interval, a positive correlation was observed between visfatin and troponin $\mathrm{T}(\mathrm{r}=+0.290 ; \mathrm{p}=0.007)$.

In the ACS group, $63.3 \%(n=38)$ were diagnosed with STEMI, $21.7 \%(n=13)$ were diagnosed with UAP, and $15.0 \%(n=9)$ with NSTEMI. There were no statistically significant differences in the visfatin level between the controls and the STEMI, NSTEMI, and UAP patients (data not shown).

\section{Discussion}

ACS is the most common cause of mortality and morbidity in the world. There are 4 pathological mechanisms in ACS: systemic inflammation with plaque rupture, plaque rupture without systemic inflammation, erosion of plaque, and plaque without thrombus [17].

An atherosclerotic plaque is composed of both intracellular and extracellular lipid-containing vascular smooth muscle cells and inflammatory cells [3]. Excessive adipose tissue surrounding the blood vessels may lead to increased perivascular fat, and thus may stimulate an inflammatory state. A chronic state of inflammation in the adipose tissue causes an increase in the secretion of proinflammatory cytokines, such as interleukin 6 (IL-6), adiponectin, and TNF-a, which might also cause endothelial dysfunction [18]. While inflammation is associated with all forms of atherosclerotic plaques, stable plaques are characterized by chronic inflammation and unstable plaques by acute inflammation. The pathogenic role of macrophages and lymphocytes in plaque destabilization is believed to be associated with the secretion of cytokines and lytic enzymes, thereby predisposing a lesion to rupture. The adipose tissuederived circulating inflammatory markers are thus important in this process. Since pro-inflammatory cytokines and chemokines are thought to be responsible for plaque rupture, anti-inflammatory therapy and immune-modulatory treatment are under investigation [4].

There are some conflicting data in the literature regarding TNF-a level in patients with coronary heart disease. Some studies have suggested that TNF- $a$, as the main mediator of inflammation, is present in atherosclerotic lesions and causes 
Table 3. Visfatin, TNF, troponin T, and CK-MB levels during T0, T1, and T2

\begin{tabular}{|c|c|c|c|c|c|}
\hline & $\begin{array}{l}\text { T0 } \\
\text { (mean/mean rank) }\end{array}$ & $\begin{array}{l}\text { T1 } \\
\text { (mean/mean rank) }\end{array}$ & $\begin{array}{l}\text { T2 } \\
\text { (mean/mean rank) }\end{array}$ & P value* & post hoc** \\
\hline Visfatin (ng/mL) & $4.01 \pm 6.23 / 2.36$ & $1.80 \pm 3.47 / 1.81$ & $1.72 \pm 2.67 / 1.83$ & 0.005 & $\mathrm{~T} 0>(\mathrm{T} 1=\mathrm{T} 2)$ \\
\hline TNF-a (pg/mL) & $12.77 \pm 6.08 / 2.39$ & $9.96 \pm 3.53 / 1.99$ & $8.89 \pm 3.09 / 1.61$ & $<0.001$ & $\mathrm{~T} 0>\mathrm{T} 1>\mathrm{T} 2$ \\
\hline $\mathrm{TnT}(\mathrm{ng} / \mathrm{mL})$ & $1.74 \pm 3.49 / 1.61$ & $3.11 \pm 4.48 / 2.21$ & $3.56 \pm 4.19 / 2.18$ & $<0.001$ & $\mathrm{~T} 0<(\mathrm{T} 1=\mathrm{T} 2)$ \\
\hline CK-MB (U/L) & $23.56 \pm 28.04 / 1.87$ & $53.36 \pm 62.70 / 2.06$ & $72.07 \pm 110.65 / 2.07$ & 0.186 & NS \\
\hline
\end{tabular}

*Friedman test; ${ }^{* *}$ Wilcoxon test.

T0: 0-6 hours, T1: 6-12 hours, and T2: 12-24 hours from onset.

CK-MB: creatine kinase-MB; TNF-a: tumor necrosis factor alpha; TnT: troponin T.

\begin{tabular}{|c|c|c|}
\hline & \multicolumn{2}{|c|}{ Visfatin } \\
\hline & $\mathbf{r}$ & $\mathbf{p}$ \\
\hline Troponin T & 0.290 & $0.007^{* *}$ \\
\hline TNF-a & -0.089 & 0.429 \\
\hline CK-MB & 0.195 & 0.070 \\
\hline
\end{tabular}

*Pearson correlation test; ${ }^{* *} \mathrm{p}<0.01$

T0: 0-6 hours after onset.

CK-MB: creatine kinase-MB; TNF-a: tumor necrosis factor alpha.

progression and ruptures in atherosclerotic plaques [7, 8, 19]. A study revealed that the TNF-a levels from epicardial and abdominal adipose tissue were higher in patients with myocardial infarction and UAP than in controls [20], similar to our findings. Kręcki et al.[21] found significantly higher TNF-a levels in coronary heart disease patients than in their controls. However, in a study including ischemic coronary patients and controls, Djordjevic et al.[22] did not find a statistically significant difference between the TNF-a level of the patients and that of the controls. Torre-Amione et al.[23] reported that TNF-a concentrations were significantly greater in patients with ischemic heart disease. It has been suggested that TNF- $a$ is an important contributor to cardiomyocyte death post MI [24]. In our study, the TNF-a level was significantly higher in the patient group than in the control group in the first 6 hours due to inflammation, which is consistent with the literature. However, the TNF-a level decreased significantly after the first 6 hours (T1). Therefore, we believe that the use of TNF-a in the monitoring of ACS patients would not be beneficial.

Adipose tissue is an endocrine organ which can secrete adipocytokines like visfatin, TNF- $a$, adiponectin, leptin, and resistin [25]. In obese patients, macrophages in white adipose tissue were shown to be responsible for the production of visfatin more than adipocytes [26]. Visfatin is also released by the adipose tissue of the epicardium and may influence cardiac activity. A study demonstrated that visfatin levels in abdominal and epicardial adipose tissue were significantly greater in coronary artery disease patients in comparison with controls
[27]. Moreover, the serum visfatin levels were positively related to the fat thickness of the epicardium. Therefore, visfatin is considered to be a serious risk factor for coronary artery disease patients [27].

Visfatin displays proinflammatory activity in human monocytes and vascular endothelial cells $[28,29]$. Visfatin has been described in the literature as activating endothelial nitric oxide synthase and improving endothelial cell function via angiogenesis [30]. Essentially, visfatin was found to be a significant protective protein in endothelial cells by prohibiting endothelial cells from aging and injury [31]. Visfatin can be linked to inflammatory actions of endothelial cells [32]. Visfatin exhibits an essential role in inflammation and oxidation, with possible leads to endothelial dysfunction [33].

However, the precise role of visfatin remains controversial. It has been shown to have a proinflammatory effect, since it induced the expression of TNF-a and interleukin 6 in leukocytes [29], and it is called a harmful agent because of so-called proinflammatory effects in cardiovascular and metabolic disorders [20]. A meta-analysis [34] reported that in obese subjects with type 2 diabetes mellitus [35] and metabolic syndrome, elevated visfatin levels were determined to be risk factors for cardiovascular disease [36]. Higher visfatin levels are also related to high blood pressure and higher levels of C-reactive protein and low-density lipoprotein cholesterol (LDL-C) [36]. There is also a direct correlation between higher visfatin levels and cardiac enzymes. Lu et al.[37] suggested that visfatin might be a marker of increased cardiovascular risk. Contrary to those findings, potential beneficial effects of visfatin have been determined by other researchers. Smith et al.[38] reported that visfatin level had a positive correlation with the beneficial lipoproteins high-density lipoprotein cholesterol and apolipoprotein A1. In another study, Lim et al.[39] observed a reduction in infarct size with visfatin treatment in a murine model. In another study, the visfatin level was found to be upregulated in rat heart tissue with wine consumption, possibly by the cardioprotective components of hydroxytyrosol resveratrol and tyrosol, [40] implying that visfatin may be cardioprotective. Hsu et al.[41] suggested that visfatin can protect against MI via coordinating autophagy of cardiomyocytes. Alternatively, Choi et al.[42] evaluated lipocalin-2 and visfatin levels in coronary heart disease patients and they found that 
visfatin levels were not significantly different between the coronary artery disease patients and controls.

Visfatin is known to be an inflammatory protein associated with plaque destabilization and ACS [12,43]. Chiu et al.[44] histochemically examined visfatin in leukocytes isolated from the blood of patients with acute STEMI and from macrophages isolated from coronary ruptured plaques. They suggested that visfatin might play a role in atherosclerotic plaque rupture. Similar to their findings, in our study, visfatin levels in patients with ACS were elevated in the first 6 hours after the onset of symptoms, which Chiu et al. explained as an accelerated monocyte and neutrophil yield in correlation with the visfatin level. Yang et al.[45] suggested that elevated plasma visfatin levels increased the risk of $\mathrm{Ml}$, and that visfatin may be a promising biomarker for MI. Lu et al.[37] found that plasma visfatin levels were significantly higher in MI cases and that the elevated visfatin level were correlated with higher cardiac enzymes levels. They proposed that increased plasma visfatin may be linked to myocardial damage. However, the mechanism of visfatin in cardiovascular diseases still needs to be further elucidated. In our study, the visfatin level was not statistically significantly greater in the ACS patients than in the healthy subjects in first 6 hours. There was a positive correlation between visfatin and troponin T in the first 6 hours; however, according to our statistical data, visfatin was not superior to classic cardiac biomarkers such as troponin for the early diagnosis and monitoring of ACS. We think that the role of visfatin in the early period of ACS may be better understood by examining the changes in visfatin level in first 6 hours of ACS. Due to both plaque destabilization and cardioprotective effects, visfatin may be a dual effective adipokine, such as adiponectin. Further studies are needed for the complete clarification of the pathophysiological mechanisms of visfatin.

Recently, a goal of physicians has been to use clinical markers to identify patients at risk for ACS. Wang et al.[46] suggested that visfatin may be an independent risk factor of coronary heart disease and that increased levels of visfatin may be involved in the occurrence and development of coronary heart disease. The Jupiter trial demonstrated that a daily dose of $20 \mathrm{mg}$ of rosuvastatin significantly lowered cardiovascular mortality in lowand/or intermediate-risk patients with LDL-C levels of less than $130 \mathrm{mg} / \mathrm{dL}$ and high-sensitivity C-reactive protein levels over 2 $\mathrm{mg} / \mathrm{L}$. However, no single biomarker can sufficiently predict the risk for coronary artery disease [47]. For example, multimarker risk assessment tools are better than LDL alone [48]. We think that, since it increases in the early period of ACS, visfatin may be a helpful parameter added to a multimarker panel for initial protection of low and moderate risk patients.

Visfatin was first investigated in our study as a biomarker for ACS monitoring. Classic cardiac markers, such as troponins and CK-MB, have already been used in the diagnosis and monitoring of patients with ACS. Cardiac troponins have shown to be advantageous as a powerful risk assessment tool, having greater specificity and sensitivity, and making detection of re- cent $\mathrm{MI}$ possible up to 2 weeks after onset, and being useful in the selection of therapy. However, the low sensitivity in early period of $\mathrm{Ml}$ and requirements of repeated measurements 8 to 12 hours after onset, when results are negative, are disadvantages of the troponins [49]. In our study, increased visfatin levels in the early period of ACS decreased after first 6 hours. After the first 12 hour period, no significant difference in visfatin level was found between $\mathrm{T} 1$ and $\mathrm{T} 2$ measurements. The recent development of a high-sensitive cardiac troponin $T$ assay permits detection of very low levels of troponin T. Using the high-sensitive cardiac troponin T assay improves the overall diagnostic effectivity in patients with uncertain acute $\mathrm{Ml}$, while a negative result also has a high negative predictive value. In emergency patients with acute Ml symptoms, high-sensitive cardiac troponin T significantly improves the early diagnosis of acute Ml in comparison with the standard troponin T assay [50].

\section{Conclusion}

In conclusion, visfatin demonstrated a significant positive correlation with troponin-T. Increased visfatin levels decreased significantly after the first 6 hours. Therefore, visfatin cannot be a good biomarker in the monitoring of ACS patients. Although visfatin revealed no superiority to troponins in the early diagnosis and monitoring of ACS, since its increase is correlated with troponin $\mathrm{T}$, it could be an addition to a multimarker panel used in the first 6 hours. In order to understand the role of visfatin in the early period of ACS, the pathophysiological mechanisms have to be further clarified.

\section{Conflict of interest: None declared.}

Ethics Committee Approval: The medical ethics committee of Manisa Celal Bayar University Faculty of Medicine approved this study. (approval number: 20478486-0.50.04.04)

Financial Disclosure: This article was supported by a grant from the Scientific Research Projects Unit of Manisa Celal Bayar University (Project No: 2006-124).

Peer-review: Externally peer-reviewed.

Authorship contributions: Concept - Y.G., O.B.; Design - Y.G., O.B.; Supervision - Y.G., O.B., C.U.; Fundings - Y.G., O.U., G.D.H.; Materials - Y.G., Ö.B., O.Ü., M.A.; Data collection \&/or processing Y.G., O.U., M.A., G.D.H.; Analysis and/or interpretation - Y.G., G.D.H., S.C., O.B., C.U.; Literature search - Y.G., S.C., M.A.; Writing - Y.G., S.C.; Critical review -Y.G., O.B., C.U.

\section{References}

1. Rosamond W, Flegal K, Furie K, Go A, Greenlund K, Haase N, et al; American Heart Association Statistics Committee and StrokeStatistics Subcommittee. Heart disease and stroke statistics--2008 update: a report from the American Heart Association Statistics Committee and StrokeStatistics Subcommittee. Circulation 2008;117:e25-146. [CrossRef] 
2. Makki N, Brennan TM, Girotra S. Acute coronary syndrome. J Intensive Care Med 2015;30:186-200. [CrossRef]

3. Braganza DM, Bennett MR. New insights into atherosclerotic plaque rupture. Postgrad Med J 2001;77:9-8. [CrossRef]

4. Boyle JJ, Weissberg PL, Bennett MR. Tumor necrosis factor-alpha promotes macrophage-induced vascular smooth muscle cell apoptosis by direct and autocrine mechanisms. Arterioscler Thromb Vasc Biol 2003;23:1553-8. [CrossRef]

5. Kershaw EE, Flier JS. Adipose tissue as an endocrine organ. J Clin Endocrinol Metab 2004;89:2548-66. [CrossRef]

6. Fantuzzi G. Adipose tissue, adipokines, and inflammation. J Allergy Clin Immunol 2005;115:911-9. [CrossRef]

7. Xiao N, Yin M, Zhang L, Qu X, Du H, Sun X, et al. Tumor necrosis factor-alpha deficiency retards early fatty-streak lesion by influencing the expression of inflammatory factors in apoE-null mice. Mol Genet Metab 2009;96:239-44. [CrossRef]

8. Boesten LS, Zadelaar AS, van Nieuwkoop A, Gijbels MJ, de Winther MP, Havekes LM, et al. Tumor necrosis factor-alpha promotes atherosclerotic lesion progression in APOE*3-Leiden transgenic mice. Cardiovasc Res 2005;66:179-85.

9. Fukuhara A, Matsuda M, Nishizawa M, Segawa K, Tanaka M, Kishimoto $K$, et al. Visfatin: a protein secreted by visceral fat that mimics the effects of insulin. Science 2005;307:426-30.

10. Ognjanovic S, Bao S, Yamamoto SY, Garibay-Tupas J, Samal $B$, Bryant-Greenwood GD. Genomic organization of the gene coding for human pre-B-cell colony enhancing factor and expression in human fetal membranes. J Mol Endocrinol 2001;26:107-17. [CrossRef]

11. Guzik TJ, Mangalat D, Korbut R. Adipocytokines-novel link between inflammation and vascular function? J Physiol Pharmacol 2006;57:505-28.

12. Dahl TB, Yndestad A, Skjelland M, Øie E, Dahl A, Michelsen A, et al. Increased expression of visfatin in macrophages of human unstable carotid and coronary atherosclerosis: possible role in inflammation and plaque destabilization. Circulation 2007;115:972-80. [CrossRef]

13. Sonoli SS, Shivprasad S, Prasad CV, Patil AB, Desai PB, Somannavar MS. Visfatin-a review. Eur Rev Med Pharmacol Sci 2011;15:9-14.

14. Klein-Wieringa IR, van der Linden MP, Knevel R, Kwekkeboom JC, van Beelen E, Huizinga TW, et al. Baseline serum adipokine levels predict radiographic progression in early rheumatoid arthritis. Arthritis Rheum 2011;63:2567-74. [CrossRef]

15. Morrow DA, Cannon CP, Jesse RL, Newby LK, Ravkilde J, Storrow $A B$, et al. National Academy of Clinical Biochemistry. National Academy of Clinical Biochemistry Laboratory Medicine Practice Guidelines: clinical characteristics and utilization of biochemical markers in acute coronary syndromes. Circulation 2007;115:e356-75. [CrossRef]

16. Jaffe AS, Babuin L, Apple FS. Biomarkers in acute cardiac disease: the present and the future. J Am Coll Cardiol 2006;48:1-11.

17. Crea F, Liuzzo G. Pathogenesis of acute coronary syndromes. J Am Coll Cardiol 2013;61:1-11. [CrossRef]

18. Gustafson B. Adipose tissue, inflammation and atherosclerosis. J Atheroscler Thromb 2010;17:332-41. [CrossRef]
19. Song HY, Régnier $\mathrm{CH}$, Kirschning CJ, Goeddel DV, Rothe $M$. Tumor necrosis factor (TNF)-mediated kinase cascades: bifurcation of nuclear factor-kappaB and c-jun N-terminal kinase (JNK/SAPK) pathways at TNF receptor-associated factor 2. Proc Natl Acad Sci USA 1997;94:9792-6. [CrossRef]

20. Cheng KH, Chu CS, Lee KT, Lin TH, Hsieh CC, Chiu CC, et al. Adipocytokines and proinflammatory mediators from abdominal and epicardial adipose tissue in patients with coronary artery disease. Int J Obes (Lond) 2008;32:268-74.

21. Krecki R, Drozdz J, Szcześniak P, Orszulak-Michalak D, Krzemińska-Pakuła M. Novel atherogenesis markers for identification of patients with a multivessel coronary artery disease. Kardiol Pol 2008;66:1173-80.

22. Djordjevic VB, Stojanovic I, Cosic V, Zvezdanovic L, Deljanin-IIic $M$, Dimic $S$, et al. Serum neopterin, nitric oxide, inducible nitric oxide synthase and tumor necrosis factor-alpha levels in patients with ischemic heart disease. Clin Chem Lab Med 2008;46:1149-55. [CrossRef]

23. Torre-Amione G, Kapadia S, Lee J, Durand JB, Bies RD, Young $\mathrm{JB}$, et al. Tumor necrosis factor-alpha and tumor necrosis factor receptors in the failing human heart. Circulation 1996;93:70411. [CrossRef]

24. Meldrum DR, Cleveland JC Jr, Cain BS, Meng X, Harken AH. Increased myocardial tumor necrosis factor-alpha in a crystalloid-perfused model of cardiac ischemia-reperfusion injury. Ann Thorac Surg 1998;65:439-43. [CrossRef]

25. Smith CC, Yellon DM. Adipocytokines, cardiovascular pathophysiology and myocardial protection. Pharmacol Ther 2011;129:206-19. [CrossRef]

26. Curat $C A$, Wegner $V$, Sengenès $C$, Miranville $A$, Tonus $C$, Busse $R$, et al. Macrophages in human visceral adipose tissue: increased accumulation in obesity and a source of resistin and visfatin. Diabetologia 2006;49:744-7. [CrossRef]

27. Malavazos AE, Ermetici F, Cereda E, Coman C, Locati M, Morricone $L$, et al. Epicardial fat thickness: relationship with plasma visfatin and plasminogen activator inhibitor-1 levels in visceral obesity. Nutr Metab Cardiovasc Dis 2008;18:523-30.

28. Kim SR, Bae YH, Bae SK, Choi KS, Yoon KH, Koo TH, et al. Visfatin enhances ICAM-1 and VCAM-1 expression through ROS-dependent NF-kappaB activation in endothelial cells. Biochim Biophys Acta 2008;1783:886-95. [CrossRef]

29. Moschen AR, Kaser A, Enrich B, Mosheimer B, Theurl M, Niederegger $\mathrm{H}$, et al. Visfatin, an adipocytokine with proinflammatory and immunomodulating properties. J Immunol 2007;178:1748-58. [CrossRef]

30. Lovren F, Pan Y, Shukla PC, Quan A, Teoh H, Szmitko PE, et al. Visfatin activates eNOS via Akt and MAP kinases and improves endothelial cell function and angiogenesis in vitro and in vivo: translational implications for atherosclerosis. Am J Physiol Endocrinol Metab 2009;296:E1440-9. [CrossRef]

31. Borradaile NM, Pickering JG. Polyploidy impairs human aortic endothelial cell function and is prevented by nicotinamide phosphoribosyltransferase. Am J Physiol Cell Physiol 2010;298:C66-74. [CrossRef]

32. Bae YH, Park HJ, Kim SR, Kim JY, Kang Y, Kim JA, et al. Notch1 
mediates visfatin-induced FGF-2 up-regulation and endothelial angiogenesis. Cardiovasc Res 2011;89:436-45. [CrossRef]

33. Xia M, Zhang C, Boini KM, Thacker AM, Li PL. Membrane raft-lysosome redox signalling platforms in coronary endothelial dysfunction induced by adipokine visfatin. Cardiovasc Res 2011;89:401-9. [CrossRef]

34. Chang YH, Chang DM, Lin KC, Shin SJ, Lee YJ. Visfatin in overweight/obesity, type 2 diabetes mellitus, insulin resistance, metabolic syndrome and cardiovascular diseases: a meta-analysis and systemic review. Diabetes Metab Res Rev 2011;27:515-27. [CrossRef]

35. Uslu S, Kebapçi N, Kara M, Bal C. Relationship between adipocytokines and cardiovascular risk factors in patients with type 2 diabetes mellitus. Exp Ther Med 2012;4:113-120.

36. Filippatos TD, Tsimihodimos V, Derdemezis CS, Gazi IF, Saougos V, Mikhailidis D, et al. Increased plasma visfatin concentration is a marker of an atherogenic metabolic profile. Nutr Metab Cardiovasc Dis 2013;23:330-6. [CrossRef]

37. Lu LF, Wang CP, Yu TH, Hung WC, Chiu CA, Chung FM, et al. Interpretation of elevated plasma visfatin concentrations in patients with ST-elevation myocardial infarction. Cytokine 2012;57:74-80. [CrossRef]

38. Smith J, Al-Amri M, Sniderman A, Cianflone K. Visfatin concentration in Asian Indians is correlated with high density lipoprotein cholesterol and apolipoprotein A1. Clin Endocrinol (Oxf) 2006;65:667-72. [CrossRef]

39. Lim SY, Davidson SM, Paramanathan AJ, Smith CC, Yellon DM, Hausenloy DJ. The novel adipocytokine visfatin exerts direct cardioprotective effects. J Cell Mol Med 2008;12:1395-403.

40. Mukherjee S, Lekli I, Gurusamy N, Bertelli AA, Das DK. Expression of the longevity proteins by both red and white wines and their cardioprotective components, resveratrol, tyrosol, and hydroxytyrosol. Free Radic Biol Med 2009;46:573-8.

41. Hsu CP, Hariharan N, Alcendor RR, Oka S, Sadoshima J. Nic- otinamide phosphoribosyltransferase regulates cell survival through autophagy in cardiomyocytes. Autophagy 2009;5:1229-31. [CrossRef]

42. Choi KM, Lee JS, Kim EJ, Baik SH, Seo HS, Choi DS, et al. Implication of lipocalin-2 and visfatin levels in patients with coronary heart disease. Eur J Endocrinol 2008;158:203-7. [CrossRef]

43. Liu SW, Qiao SB, Yuan JS, Liu DQ. Association of plasma visfatin levels with inflammation, atherosclerosis and acute coronary syndromes (ACS) in humans. Clin Endocrinol (Oxf) 2009;71:202-7. [CrossRef]

44. Chiu CA, Yu TH, Hung WC, Lu LF, Chung FM, Tsai IT, et al. Increased expression of visfatin in monocytes and macrophages in male acute myocardial infarction patients. Mediators Inflamm 2012;2012:469852. [CrossRef]

45. Yang Y, Li Z, Tao HF, Qi XY, Wang WL, Yang L, et al. An elevated plasma level of visfatin increases the risk of myocardial infarction. Genet Mol Res 2014;13:8586-95. [CrossRef]

46. Wang XH, Dou LZ, Gu C, Wang XQ. Plasma levels of omentin-1 and visfatin in senile patients with coronary heart disease and heart failure. Asian Pac J Trop Med 2014;7:55-62. [CrossRef]

47. Ridker PM; JUPITER Study Group. Rosuvastatin in the primary prevention of cardiovascular disease among patients with low levels of low-density lipoprotein cholesterol and elevated high-sensitivity C-reactive protein: rationale and design of the JUPITER trial. Circulation 2003;108:2292-7. [CrossRef]

48. Field PA, Vasan RS. LDL-Cholesterol Is Not the Only Clinically Relevant Biomarker for Coronary Artery Disease or Acute Coronary Syndrome. Clin Pharmacol Ther 2018;104:232-4.

49. Shapiro BP, Babuin L, Jaffe AS. Cardiac biomarkers. In: Murphy JG, Lloyd MA, editors. Mayo Clinic Cardiology: Concise Textbook. 3rd ed. Rochester, MN: Mayo Clinic Scientific Press: 2007. p. 773-80. [CrossRef]

50. Xu RY, Zhu XF, Yang Y, Ye P. High-sensitive cardiac troponin T. J Geriatr Cardiol 2013;10:102-9. 